\title{
Acidentes perfurocortantes envolvendo material biológico: o dizer e o fazer de estudantes de um curso de graduação em Odontologia
}

\author{
William José Mazutti*, Silvia Leticia Freddo**, Deison Alencar Lucietto*** \\ * Cirurgião-dentista egresso da FASURGS \\ ** Professora, Curso de Odontologia, UCEFF Faculdades \\ *** Professor, Instituto de Saúde Coletiva, UFF
}

Recebido em 10/01/2018. Aprovado em 22/09/2018.

\begin{abstract}
Resumo
Considerando a importância da adoção de medidas de biossegurança desde a formação dos cirurgiõesdentistas, este estudo teve como objetivo descrever a prevalência de acidentes com perfurocortantes, onde e como ocorrem, assim como verificar as atitudes de estudantes de Odontologia em relação à sua prevenção e manejo. Tratou-se de estudo observacional quanti-qualitativo com 58 concluintes de um curso de graduação do Rio Grande do Sul. Foram utilizados um questionário e um roteiro de observação participante. Constatou-se prevalência de $31 \%$ de acidentes envolvendo material biológico. Os locais de maior ocorrência foram a clínica de periodontia e a central de esterilização. Sondas periodontais, pontas ultrassônicas e limas endodônticas foram os instrumentais mais envolvidos. Identificaram-se falhas no processo de notificação e limitações no uso adequado de EPI, especialmente na central de esterilização. Aspectos como cobertura vacinal, lavagem das mãos e rotinas de desinfecção necessitam acompanhamento. $\mathrm{O}$ desrespeito às normas de biossegurança e a desatenção figuraram como importantes fatores de risco observados. Os achados demandam investimentos em educação continuada com vistas à conscientização da comunidade acadêmica, indispensável para a prevenção de acidentes e preservação da saúde dos futuros cirurgiões-dentistas. Palavras-chave: Acidentes de Trabalho. Estudantes de Odontologia. Conhecimento. Atitude. Exposição a Agentes Biológicos.
\end{abstract}

\section{INTRODUÇÃO}

Acidentes

com

instrumentos

perfurocortantes frequentemente envolvem materiais biológicos e se relacionam com a transmissão de doenças ${ }^{1}$, em função da presença de bactérias, vírus, protozoários e fungos². A elevada prevalência desses acidentes com estudantes em disciplinas de clínica odontológica é preocupante e tem sido discutida em estudos nacionais ${ }^{3-6}$. Observa-se o incremento do número de casos com o avanço dos estudantes para as atividades em ambiente clínico ${ }^{7}$. 
Os acidentes com perfurocortantes podem ser causados durante o procedimento e após os atendimentos ${ }^{1}$ e tem como fatores envolvidos o tempo na prestação dos atendimentos, a inexperiência ${ }^{7}$, o posicionamento inadequado do profissional e os descuidos na manipulação de instrumentos contaminados ${ }^{8}$. Muitos acontecem durante a desinfecção e a lavagem dos instrumentais, evidenciando que a desatenção e a negligência no uso de EPI completo é importante fator para que ocorram contaminações ${ }^{7}$.

Em função disso, as atividades em âmbito odontológico exigem a adoção de medidas preventivas específicas ${ }^{9}$ como a vacinação contra hepatite $\mathrm{B}$, influenza, tríplice viral e dupla tipo adulto $^{2,9-11}$; o uso de EPI completo ${ }^{2,7,10,12}$; a criteriosa lavagem das mãos; e os cuidados na desinfecção e esterilização de $\operatorname{artigos}^{2,10}$. A adoção de medidas de biossegurança é imprescindível para a manutenção da saúde da equipe odontológica e deve ser incentivada desde a formação ${ }^{10,11}$. A aplicação de conhecimentos, técnicas e equipamentos permite minimizar riscos ocupacionais, evitar a transmissão de doenças e favorecer a saúde e o bem-estar ${ }^{10,12,13}$.

Embora os cursos de Odontologia disponibilizem conteúdos e/ou disciplinas de Biossegurança e Ergonomia, nem sempre os mesmos são traduzidos em atitudes nas atividades práticas. Em caso de tais situações, além dos cuidados imediatos, deve-se fazer a notificação por meio da Comunicação de Acidente de Trabalho (CAT) e ser verificada a necessidade de quimioprofilaxia (contra hepatite $\mathrm{B}$ e vírus da imunodeficiência humana) e o acompanhamento sorológico $2,9,14$

Mesmo esse sendo um assunto de grande importância na formação dos cirurgiões-dentistas, verifica-se limitado nível de informação de estudantes sobre o manejo após os acidentes, negligência no uso de equipamentos de proteção individual (EPI) e descaso na notificação dos acidentes, os quais dificultam o diagnóstico da situação atual nas instituições de ensino e limitam o desenvolvimento de medidas preventivas $3,4,15,16$.

Considerando o exposto, este estudo teve como objetivo descrever a prevalência de acidentes com perfurocortantes, onde e como ocorrem, assim como verificar as atitudes de estudantes de Odontologia em relação à sua prevenção e manejo, propondo um contraponto entre o dizer e o fazer no cotidiano de um curso de graduação.

\section{MATERIAIS E MÉTODOS}

Tratou-se de estudo observacional transversal com abordagem quanti-qualitativa em um curso de Odontologia do Rio Grande do Sul. A pesquisa seguiu as recomendações da Resolução CNS N . 466/2012 e foi aprovada pelo Comitê de Ética em Pesquisa institucional (Parecer $\mathrm{N}^{\circ}$ 1.273.458). Foram incluídos estudantes do último ano do curso de graduação, devidamente matriculados nas disciplinas de Clínica de Odontopediatria e de Clínicas Odontológicas Integradas e que consentiram sua participação mediante assinatura do Termo de Consentimento Livre e Esclarecido (TCLE). Foram excluídos estudantes não localizados em sala após três tentativas.

Como instrumento quantitativo foi utilizado questionário com 16 questões de múltipla escolha ${ }^{17,18}$ para levantar a prevalência de acidentes com perfurocortantes e verificar as atitudes de estudantes quanto à sua prevenção e manejo. Este instrumento foi previamente testado, em relação à clareza das questões, com três cirurgiões-dentistas recém-egressos do mesmo curso. Os dados coletados foram tabulados e analisados quantitativamente, por meio de medidas de frequência e porcentagem, no Programa BioEstat 5.0.

Como abordagem qualitativa foi utilizada a técnica da observação participante ${ }^{19}$, aplicada durante 12 turnos, com duração aproximada de 
quatro horas cada, em dias aleatórios e intercalados, sendo oito nas dependências das clínicas odontológicas e quatro na central de esterilização. Foi utilizado um roteiro de observação para guiar nos aspectos a serem observados. As observações, a cada hora, foram intercaladas com períodos para anotações em um diário de campo, as quais posteriormente foram transcritas em banco de dados. As informações coletadas foram analisadas qualitativamente segundo preceitos da Hermenêutica-Dialética ${ }^{19}$. Foram construídas categorias gerais, envolvendo informações sobre as atitudes observadas (uso de EPI; lavagem das mãos; utilização de barreiras de proteção nos equipos; desinfecção dos consultórios; organização do ambiente clínico; situações de risco a acidentes com perfurocortantes; e manejo de instrumentais na central de esterilização). Essas categorias foram analisadas separadamente. De posse desse material, foi realizada a síntese dos achados das observações.

\section{RESULTADOS}

\section{O dizer dos estudantes}

Cinquenta e oito estudantes participaram do estudo, sendo $30(51,7 \%)$ do penúltimo e 28 $(48,3 \%)$ do último semestre. Quanto ao sexo, 37 $(63,8 \%)$ eram mulheres. As idades variaram de 20 a 56 anos, com média de 26 anos.

Dezoito estudantes $(31,0 \%)$ relataram ter sofrido acidentes envolvendo material biológico ao longo do curso de Odontologia. Desses, um aluno $(5,6 \%)$ relatou ter sofrido três acidentes. Quando questionados sobre o local do primeiro acidente, verificou-se maior número de ocorrências nas clínicas de Periodontia e na central de esterilização, relatados por 38,9\% deles. Houve maior prevalência durante a realização de procedimentos odontológicos $(55,6 \%)$, seguido da situação de lavagem do instrumental $(27,7 \%)$. Os instrumentais mais envolvidos no primeiro acidente foram a sonda exploradora e as pontas de ultrassom, referidos por $33,3 \%$. Os dedos das mãos foram os locais mais acometidos $(66,7 \%)$ e as lesões percutâneas foram as mais prevalentes (77,8\%) (tabela 1).

Doze estudantes $(66,7 \%)$ realizaram algum tipo de comunicação sobre o acidente. A metade dos acidentados $(n=9)$ relatou ter feito comunicado do primeiro acidente ao professor responsável pela clínica. Apenas dois estudantes $(11,1 \%)$ efetuaram devidamente a CAT. Um estudante informou ter comunicado um colega sobre o acidente sendo, por isso, enquadrado como outros (tabela 1). Todos os acidentados informaram que estavam imunizados contra a hepatite B no momento do acidente.

Em relação à situação vacinal contra hepatite B, 50 estudantes $(86,2 \%)$ estavam imunizados em três doses (tabela 2).

Nos atendimentos clínicos, todos os estudantes informaram fazer uso de luva e gorro, mesmo que combinados a outros itens; $70,2 \%$ informaram utilizar sobreluvas descartáveis e $12,3 \%$ o avental descartável, sendo este um item opcional, em função do uso de jaleco de tecido. $\mathrm{O}$ uso de EPI completo foi referido por 93,0\% dos estudantes, sendo que $68,4 \%$ utilizava sobreluvas descartáveis. O uso de EPI incompleto (faltando um ou mais itens) foi relatado por 7,0\% (tabela 2).

$\mathrm{Na}$ central de esterilização verificou-se subutilização de itens de EPI. Os itens menos utilizados, mesmo combinados a outros, foram: gorro e máscara $(50,0 \%)$; óculos de proteção $(36,2 \%)$ e avental de borracha $(17,2 \%)$. Verificouse que apenas quatro estudantes $(6,9 \%)$ utilizavam o EPI completo para a lavagem, secagem e empacotamento de instrumentais odontológicos na central de esterilização (tabela 2). Em relação à higienização das mãos, $82,5 \%$ informaram realizar a lavagem das mãos antes e depois de cada atendimento odontológico (tabela 2). 
Tabela 1. Características dos acidentes com material biológico

\begin{tabular}{lcc}
\hline Variável & n & \% \\
\hline Já sofreu algum acidente envolvendo material biológico? & & \\
Não & 40 & 69,0 \\
Sim & 18 & 31,0 \\
Caso tenha sofrido algum acidente, quantos foram? & & \\
$\quad$ Um acidente & 11 & 61,1 \\
Dois acidentes & 6 & 33,3 \\
Três acidentes & 1 & 5,6 \\
Onde aconteceu o primeiro acidente? & & \\
Clínica de Periodontia & 7 & 38,9 \\
Central de Esterilização & 7 & 38,9 \\
Clínica de Cirurgia & 2 & 11,1 \\
Clínica de Prótese Fixa & 1 & 5,6 \\
Clínica Odontológica Integrada & 1 & 5,6 \\
Em que situação aconteceu? & & \\
Durante o procedimento & 10 & 55,6 \\
Na lavagem do instrumental & 5 & 27,7 \\
No manuseio do instrumental após atendimento & 2 & 11,1 \\
No recapeamento de agulha & 1 & 5,6
\end{tabular}

Com que material ou instrumental aconteceu?

$\begin{array}{lcc}\text { Sonda exploradora } & 6 & 33,3 \\ \text { Pontas de ultrassom } & 6 & 33,3 \\ \text { Lima endodôntica } & 3 & 16,7 \\ \text { Agulha anestésica } & 2 & 11,1 \\ \text { Brocas } & 1 & 5,6\end{array}$

Em que local do corpo ocorreu a lesão?

Dedo da mão

Palma/dorso da mão

$6 \quad 33,3$

Qual foi o tipo de exposição?

Percutânea (lesões puntiformes, escoriativas, corto-contusas, etc.) $\quad 14 \quad 77,8$

Cutânea (somente contato com a pele sem perfuração) $\quad 4 \quad 22,2$

Foi emitido comunicado sobre o acidente?

Não

Sim

A quem foi dirigido o comunicado?*

$\begin{array}{lll}\text { Professor responsável pela clínica } & 9 & 50,0\end{array}$

$\begin{array}{lll}\text { Professor responsável pelo atendimento } & 2 & 11,1\end{array}$

Secretaria Municipal de Saúde - Referência Saúde do Trabalhador $\quad 2 \quad 11,1$

$\begin{array}{lll}\text { Outros } & 1 & 5,6\end{array}$

Não foi emitida $\quad \begin{array}{lr}22,2\end{array}$

* O número ultrapassa os 12 comunicados de acidente, pois estudantes comunicaram a mais de um responsável. 
Tabela 2. Atitudes dos estudantes: vacinação contra hepatite B, uso de EPI e lavagem das mãos

\begin{tabular}{|c|c|c|}
\hline Variável & $\mathbf{n}$ & $\%$ \\
\hline \multicolumn{3}{|l|}{ Vacinação contra hepatite B } \\
\hline Imunização completa (3 doses) & 50 & 86,2 \\
\hline Imunização incompleta (1 ou 2 doses) & 3 & 5,2 \\
\hline Não sabe/não lembra & 5 & 8,6 \\
\hline \multicolumn{3}{|l|}{ Uso de EPI nos atendimentos* } \\
\hline Luva & 57 & 100,0 \\
\hline Gorro & 57 & 100,0 \\
\hline Máscara & 56 & 98,2 \\
\hline Óculos de proteção & 56 & 98,2 \\
\hline Jaleco de pano & 56 & 98,2 \\
\hline Sapato fechado & 56 & 98,2 \\
\hline Sobreluvas descartáveis & 40 & 70,2 \\
\hline Avental descartável & 7 & 12,3 \\
\hline EPI completo com sobreluvas & 39 & 68,4 \\
\hline EPI completo sem sobreluvas & 14 & 24,6 \\
\hline EPI incompleto & 4 & 7,0 \\
\hline \multicolumn{3}{|l|}{ Uso de EPI na central de esterilização } \\
\hline Luva de borracha & 54 & 93,1 \\
\hline Jaleco de pano & 51 & 87,9 \\
\hline Sapato fechado & 49 & 84,5 \\
\hline Gorro & 48 & 82,6 \\
\hline Máscara & 29 & 50,0 \\
\hline Luva de procedimento & 29 & 50,0 \\
\hline Óculos de proteção & 21 & 36,2 \\
\hline Avental de borracha & 10 & 17,2 \\
\hline EPI completo & 4 & 6,9 \\
\hline EPI incompleto & 54 & 93,1 \\
\hline \multicolumn{3}{|l|}{ Momento em que costuma lavar as mãos* } \\
\hline Antes e depois do atendimento & 47 & 82,5 \\
\hline No início do turno de atendimento & 6 & 10,5 \\
\hline No término do turno de atendimento & 4 & 7,0 \\
\hline
\end{tabular}

*Uma resposta excluída em função de preenchimento inadequado.

O fazer dos estudantes nas clínicas odontológicas e na central de esterilização: as observações participantes

Foi constatado que boa parte dos alunos utilizava máscara, luvas, gorro, avental e sapato fechado nos atendimentos clínicos. Muitos, contudo, não usavam óculos de proteção.

Observou-se com frequência, no ambiente clínico, que os estudantes não realizavam adequadamente a lavagem das mãos. Essa deficiência acontecia tanto por não realizar (antes e/ou após os procedimentos) quanto por não 
respeitar a técnica antisséptica. Porém, foi verificado que antes de cirurgias todos os alunos seguiram o protocolo de lavagem das mãos.

Verificou-se que a utilização de barreiras de proteção (como filmes de PVC e embalagens plásticas) na cadeira, mocho e demais equipamentos era comum nas rotinas clínicas. Contudo, quanto à desinfecção dos equipamentos e cadeira odontológica, com o uso de álcool $70^{\circ}$, elas raramente foram realizadas. Os espaços dos boxes de atendimento encontravam-se limpos e organizados por ocasião do início das atividades, porém ao longo do tempo materiais e instrumentais contaminados ficavam sobrepostos na mesa clínica.

Durante todas as observações foram identificadas várias situações de risco a acidentes com perfurocortantes. Identificou-se que os estudantes não costumavam retirar as brocas das canetas de alta e baixa rotação, nem as pontas do ultrassom após o seu uso. Assim, frequentemente esses instrumentos pontiagudos ficavam muito próximos do perímetro de trabalho e dos movimentos executados pelos estudantes.

Constatou-se que alguns estudantes fizeram anestesias com o auxílio dos dedos para afastar os tecidos bucais, ficando susceptíveis a piques em função de qualquer desatenção ou movimento dos pacientes. Houve situações que poderiam ter sofrido perfuração com material contaminado.

$\mathrm{Na}$ central de esterilização, constatou-se que grande parte dos acadêmicos não utilizava recipientes com paredes rígidas para o transporte do instrumental contaminado.

Durante a lavagem, secagem e empacotamento, não houve o uso adequado de EPI. Em nenhum turno foi observado o uso completo destes equipamentos pelos estudantes. Os estudantes frequentemente usavam apenas jaleco e luva de borracha. Em alguns casos usavam gorro.
Observou-se alunos não fazendo o uso de luva de borracha para a lavagem do material contaminado, substituindo-a pela luva de procedimento. Havia muitas conversas paralelas entre os estudantes, ocasionando distrações. Verificou-se que nem sempre o protocolo de lavagem dos instrumentais era adequadamente seguido.

Embora existissem placas e adesivos no ambiente da central de esterilização orientando sobre os cuidados com a lavagem e solicitando o uso dos equipamentos de proteção, eles não eram respeitados.

\section{DISCUSSÃO}

$\mathrm{O}$ contato com materiais biológicos contaminados na formação do acadêmico de Odontologia acontece com mais frequência em função da sua inexperiência ${ }^{20}$. É de grande importância que se conheçam os riscos de infecção envolvidos após acidentes envolvendo perfurocortantes, os mais comuns na prática odontológica $^{9}$, especialmente após exposição a sangue e secreções, de modo a adotar condutas para sua prevenção e minimização.

Neste estudo, constatou-se prevalência de $31,0 \%$ de acidentes envolvendo exposição a material biológico entre os 58 estudantes do último ano de um curso de graduação em Odontologia. Inclusive, desses, sete $(38,9 \%)$ afirmaram ter sofrido mais que um. A prevalência encontrada foi superior à de outros estudos $\left(17,3 \%^{3}, 27,5 \%^{4}\right.$ e $\left.23,6 \% \%^{6}\right)$, porém menor que a descrita por Pinelli, Neri e Loffredo $^{5}$, com $40 \%$ de exposição ocupacional a material biológico. Destaca-se, contudo, que na presente investigação foram incluídos apenas concluintes.

Identificou-se que o maior número de acidentes aconteceu na clínica de Periodontia e na central de esterilização, de forma diversa ao encontrado na literatura, apontando como locais 
de maior frequência de acidentes a Cirurgia ${ }^{3}$, a Dentística $^{3,4}$ e Odontologia Restauradora Clínica, Clínica Integrada de Atenção Primária, Endodontia e Prótese Clínica ${ }^{6}$.

O tipo de instrumental mais envolvido em acidentes foi a sonda exploradora/periodontal e pontas ultrassônicas. Na literatura, os mais mencionados são as curetas periodontais, agulha anestésica e sonda exploradora/periodontal ${ }^{15}$ e a agulha anestésica ${ }^{3}$. Contudo, Paiva et $a l^{6}$ também referiram maior ocorrência de acidentes com sondas exploradoras. No presente estudo, os dedos foram os locais do corpo mais acometidos por acidentes $(66,7 \%)$ e as lesões percutâneas foram as mais frequentes $(77,8 \%)$, com resultados semelhantes aos encontrados no estudo de Paiva et al. ${ }^{6}$. Em função disso, ressalta-se a importância de reforçar junto aos estudantes o uso adequado de EPI e a atenção ao procedimento que está sendo realizado.

A comum falta de notificação dos acidentes nos serviços de saúde dificulta o diagnóstico e a proposição de ações preventivas ${ }^{21}$. Tal constatação foi comprovada nessa pesquisa, uma vez que $66,7 \%$ dos acidentados fez algum comunicado e apenas $11,1 \%$ realizou a CAT. Os demais, por terem informado só aos professores responsáveis, acabaram por evidenciar importantes falhas nas notificações no curso pesquisado. Identificou-se que não há entendimento claro do que significa a notificação, pois um estudante revelou ter comunicado um colega sobre o acidente. Esses fatos sugerem desinformação e/ou descaso sobre a obrigatoriedade da notificação. Nesse sentido, observa-se que, muitas vezes, alunos de Odontologia não dão a devida importância para os acidentes, deixando de fazer a notificação e tampouco procurando as orientações e ajuda necessárias ${ }^{7,22}$. Considerando essas situações, medidas informativas e de controle mais intensivas, inclusive em ambiente de ensino clínico, são incentivadas.

Dentre as várias vacinas recomendáveis aos profissionais da saúde, para o cirurgiãodentista importa especialmente a contra a hepatite $\mathrm{B}$, tendo em vista que os riscos no ambiente de trabalho odontológico ${ }^{9-11}$. Os dados encontrados nesta investigação apontam que é preciso aprimorar os programas de vacinação, uma vez que 13,8\% dos estudantes não estavam imunizados com as três doses da vacina. É preciso, então, adotar mecanismos para restringir que estudantes nessa situação desenvolvam atividades clínicas.

A necessidade de uso de EPI completo (avental/jaleco de tecido ou descartável, gorro, máscara, óculos de proteção e luvas), acrescidos do uso de roupa branca e sapatos fechados, tanto durante os atendimentos odontológicos quanto no manuseio de instrumentais odontológicos, está bem regulamentada em nível governamental $^{2,10}$ e faz parte dos cuidadospadrão recomendados pelo Ministério da Saúde ${ }^{9}$. Constatou-se, nesse estudo, que 93,0\% dos alunos relataram tal cuidado. Além disso, recomenda-se o acréscimo da luva de borracha para fazer a desinfecção, secagem e empacotamento dos materiais contaminados ${ }^{10,12}$, devido à grande possibilidade acidentes nesse processamento $^{7}$. Os resultados do presente estudo alertam para uma situação bastante delicada no processo de lavagem e esterilização dos materiais, pois apenas $6,9 \%$ dos estudantes relatou fazer o uso de EPI completo na central de esterilização.

É de suma importância que seja realizada a lavagem das mãos no início e no final do turno de trabalho, bem como antes e após o atendimento de cada paciente, sendo essa uma das medidas mais importantes para a prevenção e o controle de disseminação de infecções ${ }^{10,17}$. Nesta pesquisa, identificou-se que $17,5 \%$ dos estudantes relatou fazer a lavagem das mãos 
apenas no início ou no final do turno, evidenciando descuido na adoção dessa medida.

Nas observações participantes realizadas nas clínicas odontológicas confirmou-se que a maioria dos alunos utilizava EPI completo. Entretanto, verificou-se o mau uso de óculos de proteção e máscara em muitas situações. Embora os estudantes tenham relatado fazer uso de EPI, a forma de usá-los foi inadequada, potencializando riscos de transmissão de agentes biológicos e infecções.

Em se tratando da central de esterilização, o uso inadequado de EPI revelou descuido por parte dos estudantes na prevenção de acidentes. Além disso, percebeu-se negligência no manuseio de pontas ultrassônicas, brocas e limas endodônticas, o que pode justificar o número de acidentes com instrumentais perfurocortantes no curso investigado. Embora tenha sido observado o uso de barreiras nos equipamentos odontológicos, as rotinas de desinfecção deixaram a desejar. Para garantir a segurança dos estudantes e pacientes, faz-se necessária a utilização de substâncias químicas como álcool $70^{\circ}$, ácido peracético ou hipoclorito de sódio, desde que observadas suas concentrações e indicações $^{2}$. Em função disso, estimula-se acompanhamento mais criterioso por parte dos professores e dos próprios funcionários da central de esterilização, informando e orientando os estudantes quanto aos procedimentos.

Embora o estudo tenha como limitação sua abrangência, os achados são preocupantes e demandam medidas educacionais, preventivas e corretivas. Acredita-se que investimentos constantes em educação continuada/permanente e em campanhas para a mudança positiva de comportamentos poderão contribuir com o aprimoramento da formação e com conscientização individual e coletiva, tão necessária à minimização de acidentes com perfurocortantes em Odontologia.
Entende-se, por fim, que o método das observações participantes foi adequado para fazer um contraponto com as respostas dos questionários. Como o pesquisador fazia parte das rotinas, tanto das clínicas quanto da central de esterilização, sua presença passou desapercebida, possibilitando a apreensão da realidade sem interferências.

\section{CONCLUSÕES}

Constatou-se elevada prevalência de acidentes envolvendo material biológico entre os formandos do curso de Odontologia pesquisado, com grande potencial de causar prejuízos à sua saúde e ao seu bem-estar. As características dos acidentes, as falhas nas notificações, o uso inadequado de EPI especialmente na central de esterilização, a desatenção na realização de procedimentos e no processamento de instrumentais, bem como as lacunas na cobertura vacinal, na lavagem das mãos e nas rotinas de desinfecção denotaram importantes deficiências na prevenção de acidentes.

A abordagem quanti-qualitativa seguida, com a combinação de questionário e observação participante possibilitou compreender discordâncias entre o dizer e o fazer dos futuros cirurgiões-dentistas: mesmo que conceitos e normas de biossegurança integrem a formação, nem sempre são transformados em atitudes no dia-a-dia. Tais aspectos sugerem que $\mathrm{o}$ oferecimento de conteúdos e/ou disciplinas de Biossegurança, embora imprescindível, é insuficiente para a incorporação de práticas.

\footnotetext{
ABSTRACT

Accidents with sharp objects involving biological material: what Dentistry undergraduate students say and what they do Considering the importance of adopting biosafety measures since the initial training of dental surgeons, this study aimed to describe the prevalence, the distribution and to verify the
} 
attitudes of Dentistry students in relation to prevention and management of accidents with sharp cutting objects. This was a quantitativequalitative observational study with 58 undergraduates from a Dentistry course in Rio Grande do Sul. Questionnaires and participant observations were used. We verified a $31 \%$ prevalence of accidents involving biological material. The most frequent sites were the periodontics clinic and the sterilization center. Periodontal probes, ultrasonic tips and endodontic files were the most involved instruments. We identified failures in the notification process and limitations in the proper use of PPE, especially in the sterilization lab. Aspects such as vaccination, hand washing and disinfection routines require follow-up. Disrespect for biosafety standards and the lack of attention were important risk factors observed. The findings demand investments in ongoing education to raise awareness of the academic community, which is indispensable for accidents' prevention and preservation of the future dental surgeons' health.

Descriptors: Occupational Accidents. Dentistry Students. Knowledge. Attitude. Exposure to Biological Agents.

\section{REFERÊNCIAS}

1. Silva JA, Paula VS, Almeida AJ, Villar LM. Investigação de acidentes biológicos entre profissionais de saúde. Rev. Esc Anna Nery. 2009;13(3):508-16.

2. Brasil. Ministério da Saúde. Serviços Odontológicos: prevenção e controle de riscos. Brasília: Ministério da Saúde; 2006. [Acesso em 15 dez. 2017]. Disponível em: http://www.anvisa.gov.br/servicosaude/man uais/manual_odonto.pdf

3. Lima AA. Acidentes ocupacionais: conhecimento, atitudes e experiências de estudantes de Odontologia da Universidade Federal da Paraíba. Pesqui Bras Odontopediatria Clin Integr. 2008;8(3):32732.
4. Miotto MHMB, Rocha RM. Acidente ocupacional por material perfurocortante entre acadêmicos de Odontologia. Rev Bras Prom Saúde. 2012;25(1):97-102.

5. Pinelli C, Neri SN, Lofreddo LCM. Dental students' reports of occupational exposures to potentially infectious biological material in a Brazilian School of Dentistry. Cad Saúde Coletiva. 2016;24(2):162-9.

6. Paiva SNP, Zaroni WCS, Leite MF, Bianchi PR, Pereira TCR. Acidentes ocupacionais com material biológico em Odontologia: uma responsabilidade no ensino. Rev ABENO. 2017;17(3):76-88.

7. Orestes-Cardoso SM, Farias ABL, Pereira MRM, Orestes-Cardoso AJ, Cunha IF. Acidentes perfurocortantes: prevalência e medidas profiláticas em alunos de odontologia. Rev Bras Saúde Ocup. 2009;34(119):6-14.

8. Morrisson CT, Ferreira EL. Atenção no consultório pode evitar acidente de trabalho envolvendo material biológico. Rev CRO PR. 2014;18(86):5-10. [Acesso em 22 jul. 2015]. Disponível em: http://www.cropr. org.br/uploads/arquivo/Rv_CRO \%20ed86. $\underline{\mathrm{pdf}}$

9. Brasil. Ministério da Saúde. Exposição a materiais biológicos: protocolos de complexidade diferenciada. Brasília: Ministério da Saúde; 2011. [Acesso em 25 mai. 2016]. Disponível em: http://bvsms. saude.gov.br/bvs/publicacoes/protocolo_ex pos_mat_biologicos.pdf

10. Brasil. Ministério da Saúde. Controle de infecções e a prática odontológica em tempos de AIDS: manual de condutas. Brasília: Ministério da Saúde; 2000. [Acesso em 26 jan. 2017]. Disponível em: http://bvsms.saude.gov.br/bvs/publicacoes/ partes/manual_odonto1.pdf

11. Gir E, Netto JC, Malaguti SE, Canini SRMS, 
Hayashida M, Machado AA. Accidents with biological material and immunization against hepatitis B among students from the health area. Rev Lat Am Enfermagem. 2008;16(3):401-6.

12. Thomazini EM. Controle de infecção cruzada na prática odontológica. Piracicaba: Universidade de São Paulo; 2005.

13. Teixeira CS, Pasternak-Júnior B, SilvaSousa YTC, Correa-Silva SR. Medidas de prevenção pré e pós-exposição a acidentes perfurocortantes na prática odontológica. Rev Odonto Ciência. 2008;23(1):10-4.

14. Ministério da Saúde. Portaria No. 777, de 28 de abril de 2004. Dispõe sobre os procedimentos técnicos para a notificação compulsória de agravos à saúde do trabalhador em rede de serviços sentinela específica, no SUS. Diário Oficial da União; 2004 abr. [Acesso em 10 nov. 2015]. Disponível em: http://bvsms.saude.gov. br/bvs/saudelegis/gm/2004/prt0777_28_04 2004.html

15. Artuzi FE, Bercini F, Azambuja TWF. Acidentes pérfuro-cortantes na Faculdade de Odontologia da Universidade Federal do Rio Grande do Sul. Rev Fac Odontol Porto Alegre. 2009;50(2):26-9.

16. Lima LKOL, Tipple AFV, Barros DX, Ferreira PS, Paiva EMM, Simões LLP. Acidentes com Material Biológico Entre Estudantes de Odontologia no Estado de Goiás e o Papel das Instituições de Ensino. ROBRAC. 2012;21(58):553-9.
17. Ministério da Saúde. Sistema de Informação de Agravos de Notificação - SINAN. Brasília: Ministério da Saúde; 2005. [Acesso em 17 jan. 2016]. Disponível em: http://bvsms.saude.gov.br/bvs/publicacoes/ 07_0098_M.pdf

18. Bragança DPP, Fernandes MM, Sassi C, Francesquini Júnior L, Daruge Júnior E. Condutas do cirurgião-dentista frente a acidentes biológicos. Odonto. 2010; 18(35):24-29.

19. Minayo MCS. O desafio do conhecimento: pesquisa qualitativa em saúde. São Paulo: HUCITEC; 2008.

20. Ribeiro P, Hayashida M, Moriya $T$. Acidentes com material biológico entre estudantes de graduação em odontologia. Rev Odontol Univ Cid S Paulo. 2007;19(3):263-8.

21. Marziale MHP, Silva EJ, Haas VJ, Robazzi MLDCC. Acidentes com material biológico em hospital da Rede de Prevenção de Acidentes do Trabalho - REPAT. Rev Bras Saúde Ocup. 2007;32(115):109-19.

22. Ribeiro PHV. Acidentes com material biológico potencialmente contaminado em alunos de um curso de Odontologia do interior do estado do Paraná [dissertação]. São Paulo: Universidade de São Paulo; 2005.

\section{Correspondência para:}

Deison Alencar Lucietto

e-mail: deisonlucietto@id.uff.br

Dep. Saúde e Sociedade, Instituto de Saúde

Coletiva, Universidade Federal Fluminense

Rua Marquês do Paraná $3033^{\circ}$ andar, prédio anexo ao HUAP

24030-2100 Niterói/RJ 